\title{
TRANSPORTATION AND THE ENVIRONMENT
}

\author{
David Banister * \\ Karen Anderton \\ David Bonilla \\ Moshe Givoni \\ Tim Schwanen \\ Transport Studies Unit \\ School of Geography and the Environment \\ University of Oxford \\ South Parks Road, Oxford \\ OX1 3QY \\ United Kingdom \\ * Corresponding author \\ Phone: +44 (0)1865 285070 \\ Fax: +44 (0)1865 275885 \\ E-mail: david.banister@ouce.ox.ac.uk
}

Posted with permission from the Annual Review of Environment and Resources,

Volume 36 @ 2011 by Annual Reviews, http://www.annualreviews.org

DOI: http://dx.doi.org/10.1 146/annurev-environ-032310-112100 
Prepared for:

Annual Review of Environment and Resources, 2011

January 2011 


\title{
Table of Contents
}

1. Introduction

2. The limits to travel

2.1 Concern with transport and 'the environment' over time

3. Decarbonizing transport

3.1 Policy mix for decarbonization

4. Rethinking transport governance

4.1 The historical legacy of transport governance

4.2 Modalities of path-dependent transport governance

4.3 Opening up the paths of transport governance

5. Conclusions

6. References

\section{Key Words}

Decarbonization, governance, unsustainable growth, technological optimism, behavioral change

\begin{abstract}
(150 words)
The growth of $\mathrm{CO}_{2}$ intensive transport, mobility and the impact of transport on the environment are reviewed. The recent global exponential growth in transport is unsustainable and must end, unless the transport sector can decarbonize. The paper then examines solutions for low carbon transport systems, the behavioral options, demand reduction, the role of innovative technologies, and the means by which international agreements on pricing, standards and regulations can be effectively used. Transport brings enormous benefits to society and it has been instrumental in the globalization of the world economy, with substantial capital being invested in the material infrastructure. Transport governance also needs rethinking, to understand the major challenges, to implement major policy changes, and to address the problems of fragmented decision making. Holistic approaches, using ideas from transition management and niche development, are proposed as a framework within which both technological innovation and new patterns of travel and trade can be encompassed.
\end{abstract}




\section{Green highlights: Glossary items}

Highlights (up to 8)

1. Historically huge growth in transport and potential for much more growth

2. Little or no contribution made by the transport sector to reducing carbon dependence

3. Aviation and maritime key areas for new growth

4. Technological optimism has proved unrealistic

5. Behavioral change necessary, particularly in the rich countries

6. Travel and trade brings benefits to society and instrumental in globalization

7. Transport governance fragmented and a more holistic approach required

8. Embedded costs in infrastructure and institutions make change problematic

Future Issues (up to 8)

1. Growth likely to increase in magnitude, particularly in developing countries

2. Transport may account for more than $50 \%$ of all $\mathrm{CO}_{2}$ by 2050

3. The developed countries need to take responsibility for large scale reductions

4. Transport $\mathrm{CO}_{2}$ should be allocated on the basis of consumption, not production - this requires realistic pricing for carbon

5. Technological innovation is needed, together with effective measures that build on the savings in carbon to minimize rebound effects

6. Economies need to decouple the carbon intensity of transport from GDP growth so that less carbon is used - this means less travel and trade, shorter distances, modal shift and the use of only carbon efficient forms of transport

7. Transition theory may help the understanding and the range of effective interventions 


\section{Introduction}

The transport sector has been described as the blood system of society (1) and one which has metaphorically contracted the planet (2). Over the last century the transport of people, goods and information has increased enormously, reflecting the clear economic and societal benefits of transport. The global economy functions through (international) travel and trade, and there exist important positive feedback loops between transport and the economy, as growth of one stimulates the other (3). As well as allowing other economic sectors to function, transportation (i.e. the infrastructure, logistics and information systems that manage and direct the actual movement of vehicles, ships and airplanes) has become an important sector in the global economy in its own right (4). At the individual level, transport enables people to travel; to access employment opportunities and services including healthcare, shopping and leisure, and to maintain spatially extended social networks (5-6). There are also political benefits: in the EU, for instance, inter-urban movements of people, goods and information contribute to the European integration process and the formation of a common European identity (5). Investment in highspeed train (HST) is considered instrumental in realizing this goal, as it shrinks travel times between major European cities and thus was believed to 'shrink' the continent (7).

Cheap natural resources (oil) have allowed many people, firms and other stakeholders across the world - but especially in developed countries - to reap the benefits of transport and to travel further, more often and with almost limitless freedom. Yet, relentless travel and movement comes at a price. Modern transport is almost totally dependent on oil and $61.4 \%$ of all oil was used for transport in 2008 (8-9), and multiple problems have emerged with the growth in demand for transport. These include traffic congestion, traffic safety, urban sprawl and environmental problems such as noise, air pollution, ecosystems impacts and greenhouse gas (GHG) emissions, (10). The growth of travel demand has also heightened and exacerbated (primarily Western) concerns over peak oil, oil price volatility and energy security. Whilst discussed initially in the aftermath of the 1973 oil crisis, these issues have attracted increased attention in the past decade or so. Moreover, while other sectors of the economy can rely increasingly on alternatives, such as renewable energy sources, there are few opportunities for transport (11).

Whilst all of these issues are problematic in their own right, with distinct characteristics and implications, we consider GHG emissions to be the most pressing environmental concern. A robust response to reducing or eliminating GHG emissions from transportation would deal with a number of these other impacts as well. For these reasons, GHG emissions and the means to curb their growth in the transportation sector are the primary focus of this review. Indeed $\mathrm{CO}_{2}$ emissions feature prominently in the discourse and debates over transport and the environment, since the IPCC's $1^{\text {st }}$ Assessment Report (12) highlighted the risk associated with increasing concentration of carbon in the atmosphere. Climate models suggest that emissions in 2050 should be $50-85 \%$ lower than in 1990 to limit changes in global temperature to $2-2.4^{\circ} \mathrm{C}$ above the pre-industrial levels, and this means that GHG emissions need to peak before 2015 (13). Transport is the only major sector where emissions continue to grow, with car use, road and maritime freight and aviation being the principal contributors to GHG emissions (2). The growth in oil consumption between 1973 and 2008 has been more than 110\% (9), and global $\mathrm{CO}_{2}$ emissions from transport have increased 44\% in the period 1990-2007 (14). There are no signs that $\mathrm{CO}_{2}$ emissions from transport will decrease. Banister (15) shows that if global emissions of 
$\mathrm{CO}_{2}$ are halved between 2005 and 2050 (from 32.6Gt to 16Gt), the share of land transport across all sectors will be stable at 20-22\% in 2050 (against 22\% in 2005), but the shares of aviation and maritime transport will probably increase substantially: from $2.2 \%$ and $3.1 \%$ in 2005 to $15-18 \%$ and $15-20 \%$ in 2005 (15). This means that transport could account for over half of all $\mathrm{CO}_{2}$ emissions by 2050, and much of this future growth will occur in the rapidly growing economies such as the BRIC countries (Brazil, Russia, India and China).

Growth in transport demand may cancel out GHG reductions in other sectors (14-15). Hence, we believe that immediate and large-scale action is required that may affect the way society works, the energy sources used and the means to move about. Growth in transport needs to be decoupled from economic growth to avoid further increases in transport's environmental impacts. Changes will also be required in the way policies are implemented and the way transport institutions interact. Indeed, the governance of transport needs to be rethought to successfully address these issues. This review will highlight the most important thinking on the means to deliver this shift and discuss some of the challenges involved in achieving the ultimate goal of a low $\mathrm{CO}_{2}$ transport system.

The enormous benefits to society from transport have locked us into patterns of living dependent on long distances and complex supply chains, but this has involved substantial increases in the environmental costs. This lock-in effect translates to ever more efforts to increase the benefits of transport even when the costs exceed the benefits. The three substantive sections of the review focus on the main environmental challenges facing transport. Sections 2 and 3 draw primarily on empirical work and conceptual thinking from transport studies and economics. In section 2 the workings of contemporary transport systems, primarily in the Western world are examined through its development trajectory over the last 200 years and the substantive causes of the unprecedented growth and dependence on fossil fuel. This is followed by a review of the technologies, financial incentives and policies that could be utilized to decarbonize transport. In section 4 we critically evaluate transport governance, examine the consequences of its historical legacy and propose some ways in which this may be reconfigured. This part of the review is based on a different set of literatures and the emphasis shifts towards thinking rooted in evolutionary, complexity and sociological theories. The conclusions bring together the different literatures and some observations are offered on how the benefits from transport can be maximized, and how the reductions in transport's fossil fuel and $\mathrm{CO}_{2}$ dependence can be achieved.

\section{The limits to travel}

Transport has always been a central part of human life, with our ancestors walking around in search of food and shelter. As population grew so has the amount of transport. Technology, and literarily the invention of the wheel dramatically changed the relationship between population and the volume of transport. Other step changes were the advent of motorized transport and the development of the private car. Technological development is thus the main enabler, and partly the driver, behind the exponential growth in the average distance traveled per person per day (e.g. in France between 1800 and 2000 - Figure 1). Technology has speeded up travel, which meant shorter travel times for undertaking the same range of activities or increasing the range of 
activities that could be undertaken within a specific travel time budget (16). For example, when new bridges reduced crossing time of rivers to a few minutes, local traffic multiplied ten times in Lisbon and five times in Istanbul (17). Economic, social and political factors coupled with population growth, rising incomes and technological development fostered many other changes in the 'way of living' that further increased the volume of the transport of both people and goods. The volume of transport of course depended on supply of appropriate infrastructure.

\section{[Figure 1]}

Since the $18^{\text {th }}$ century and the industrial revolution, transport has been seen as a pre-condition for development, even if the direction of causality could not always be verified (18-19). Transport quickly became a precondition for, and very much a result of, increasing wealth. Still today, a higher level of wealth (income) tends to be associated with longer distances traveled per year, but not necessarily more or less travel time (16). Trade is also enhanced by rising incomes and by globalization processes, resulting in growth rates of freight transport that exceed growth rates of passenger transport. This is true at least since the 1990s for the world as a whole (20) and in the EU countries (4). Freight moved within and between countries accounts for roughly 50\% of energy use in total world transport (the figure includes international shipping, rail, road and air modes) (20). The transport intensity of various products was well captured in the study of "the well traveled yogurt pot”, where it was estimated that to bring one truckload of 150g strawberry yogurt pots to a distribution outlet in southern Germany, the equivalent of $1005 \mathrm{~km}$ distance needed to be covered (21). The centre of gravity of the global economy and trade has moved to Asia, with the offshoring of manufacturing capacity and freight transport activity, and $\mathrm{CO}_{2}$ emissions will become dominated by the BRIC countries, and the OECD countries will become the main importing region (22).

Increasing income, as well as the growing participation of women in the labor force and the decrease in household size, all act to increase car ownership, which in turn contributes to increased personal mobility (23-24). On the demand side, changes in values and norms have further enhanced car ownership levels, while on the supply side real term reductions in the cost of transport have also facilitated 'motorization' (25).

Economic processes are often entwined with land use changes, which also shape and are shaped by developments in transport. The emergence of cities has created a new type and level of demand for transport, as food, fuel, building materials as well as people needed to be moved between locations of production, consumption and living that were often spatially separated (26). Transport, in turn, was often the key facilitator for the expansion of cities. The construction of new railways, for instance, allowed London to expand substantially in the middle of the $18^{\text {th }}$ century (27). About a century later, the widespread use of the car allowed the further expansion of the same cities (in western countries) through sprawl, which results in specific environmental impacts (28). The increase in the size of cities resulted in a disproportionate increase in the demand for transport as various activities became more spatially separated and segregated. Land use patterns within cities became an increasingly important determinant of the volume of transport (29), especially in cities with expansive road network and high motorization levels. 
The demand for transport cannot be realized without a matching supply of infrastructure, and increasing capacity often results in more transport. Given that new infrastructure usually reduces the general cost of travel (mainly by increasing its speed), additional capacity allows latent demand to be realized and this creates new demand (30). Thus, the eras of rail expansion in the Victorian days, motorway network construction in the USA, and the construction of hub airports across the world, have all resulted in large increases in the volume of transport, partly through the above effects and also as they changed our way of living, by making us become more travel dependent (31). These new infrastructures reflect emerging new transport technologies, leading to substitution between 'old' and 'new' transport modes. On the whole, however, older modes remained important and newer ones increased their market shares by generating additional demand for transport. This is demonstrated for the USA when examining changes in the volume of transport between 1950 and 2000 (17).

The governance of transport systems has also had an important influence on the volume of travel. Air transport in its early days was not commercially viable, but was considered so important that states took control of it, by subsidizing or even providing it - this occurred as early as the late 1920s in the case of KLM and the Netherlands - and later by regulating it (32). When air transport became commercially viable, states gradually gave up ownership of their airlines and deregulated air transport (1978 in the USA and 1993 in Europe) (32-33). The main result of this change in governance is a reduction in the real cost of travel through more efficient operations (34), including the emergence of low-cost airlines (35). To some extent these regulatory changes and the introduction of competition into the market helped to produce substantial environmental benefits through a combination of technological and operational improvements. The energy intensity of the USA airlines' fleet, the largest air transport market in the world, was reduced by 60\% between 1971 and 1998. These benefits were, however, more than offset by a 300\% increase in passenger-km over the same period (36). Thus, the increased number of flights to cater for increased demand outweighed the benefits of far more fuel efficient, 'cleaner' and quieter aircraft. Other transport modes and sectors have also gone through processes of deregulation, liberalization and/or privatization (37-38). These are largely seen as successful insofar as travel cost reductions are concerned, but the lower costs have increased transport volumes. Arguably, these processes have also resulted in a fragmented and disintegrated transport system from the user perspective, making modes which can provide door-to-door service (notably the private car) more attractive (1), but at a high environmental cost. Deregulation, liberalization and/or privatization designed to correct 'market failures' in transport have probably contributed to raising its environmentally unsustainable character.

In the remarkable story of the "growth in transport", there have always been concerns with the environmental impact and 'cost' of transport for society. The Romans for example, banned traffic in cities at night to reduce noise (39:1). The nature, focus and level of this concern has continuously changed as transport evolved, but there is now a new imperative as the scientific understandings of the environment in general and how transport affects it have grown (39). Yet, this increased concern has not ‘caught up’ with our desire for travel.

\subsection{Concern with transport and 'the environment' over time}

In the decades following World War II oil was considered abundant and cheap and this contributed to the sharp increase in car use and emergence of new driving practices (especially 
solo driving) in the USA and elsewhere (40). At the same time, the perception of and attitude towards the environment started to change. The 'environment' became an item on the public agenda, very much following the publication of Rachel Carson's "Silent spring" and later "The limits to growth" by the Club of Rome (41). During the late 1960s and early 1970s, most of the important environmental institutions were formed, including the UNEP in 1973 (42). Yet, the wider environmental impacts of increasing transport were not picked up as an issue. A notable early exception was air pollution control in Los Angeles, which was partly attributed to road transport, and already in the 1940s this had led to efforts to better understand and control the problem. These efforts were, however, aimed at mitigating transport's contribution to air pollution rather than at reducing transport (43). This focus on mitigating externalities has remained a characteristic of transport policies. Concerns were expressed about the implications of growing transport, especially when congestion emerged as a real problem, but these were framed as economic rather than environmental issues (e.g. 44). The response to congestion has often been an increase in the supply of infrastructure.

The 1973 "oil crisis" was a defining moment for transport, and this has resulted in promoting alternatives to the car, for example in the Netherlands through promotion of cycling as a mode of transport (45), or in discouraging driving alone (in the USA) (40), and more generally through more fuel efficient cars (46). The 'crisis', however, did not seem to have an impact on growth in travel. Environmental concern (up to about 2000) focused on local transport issues, mainly air pollution and noise. In most places, efforts were placed on mitigating these problems while refraining from restricting (growth in) travel. An example was the ban on using lead in gasoline (which improved engine performance but adversely affected public health) (47). This ban was introduced in the USA and Canada (1970s) and later in Europe (1990s) (48).

The development of Life Cycle Assessments (LCA) methods in the 1960s and their application to transport since the late 1990s have provided new insights into the full environmental cost of transport. They take account of the non-negligible impacts of transport activities through vehicle production and scrapping, energy (fuel) extraction and production, and the full environmental impacts associated with infrastructure such as land take, materials used and the construction itself (49). LCA has demonstrated the full range of transport activities associated with the entire supply chain of products (50). Even if these lifecycle factors are included in the costs of transport (internalized), they have little effect on transport volumes (51), as the demand elasticities for travel are low and rising income levels reduce the effectiveness of higher prices (52-53).

Beyond transport, the environmental focus changed over the 1980s. Global, rather than local, environmental concerns relating to ozone depletion, climate change and biodiversity loss started to emerge on the international agenda (41). The reappearance of the 'environment' as an issue was very much reflected in the 1987 'Brundtland Report' (54). This influential report officially introduced the concept of "sustainable development", which has become the guiding principle in transport policy (55-56) but so far has not really affected transport patterns. The attention to climate change did not have much influence on demand either. Although it has been recognized for some time that air transport in particular is an important contributor to climate change (5758), demand has continued to grow, and is projected to continue to grow at high rates to 2050 at least (59). In aviation, this growth reflects an unwillingness to restrict demand but also difficulties in controlling emissions from air transport as international agreement is required (60). 
The inclusion of air transport in the European Emission Trading Scheme (from 2012 onwards) may constitute an exception in this regard, but there are doubts over the effectiveness of this scheme (61).

Despite the recognition that transport is a major contributor to GHG emissions, it usually does not feature high in the climate change debate (cf. 62). At the same time, congestion problems are considered much more important to address in transport planning through demand management, with environmental considerations been seen as desirable but not essential (63). The London congestion charging scheme exemplifies this very clearly (64).

Recently, problems of transport and environment have become prevalent in mega-cities (cities with population of over 10 million) in the developing world. Such problems are not necessarily unique in nature - they are similar to those experienced in Western Europe over the past 60 years - but they stand out in terms of magnitude and scale (65). The two main reasons for the differences between mega-cities in the developed and developing countries are the endemic congestion and the state of the vehicle fleet. The endemic congestion in mega-cities is not the result of high motorization levels, but more associated with high population growth and relatively low levels of infrastructure supply. While 20-30\% of all land is taken by roads in USA cities, the corresponding share for major cities in Asia is $10-12 \%$. In addition, an older vehicle fleet, poor maintenance practices and limited vehicle testing mean that the environmental impacts of motorization are many times worse than those in a developed nation. The reliance in many mega-cities on poor quality fuel results in high levels of pollution from particulates, lead and other local pollutants. Transport is responsible for $80-90 \%$ of the atmospheric lead in cities where leaded gasoline is still used (66). Even with relatively high levels of public transport and walking and cycling, these cities face serious air pollution impacts from transport (67). In Shanghai, for instance, vehicle use contributed $87 \%, 97 \%$ and $74 \%$ of $\mathrm{CO}, \mathrm{HC}$ and $\mathrm{NO}_{\mathrm{x}}$ emissions in 2002, respectively (68). But pollution and associated health problems are superseded by (road) safety as transport's key negative externality. About $85 \%$ of the 1.2 million people killed annually in road accidents across the globe lived in developing and emerging economies, and this is now the major source of child mortality (5-14 year olds) in low and middle income countries (66).

Increasing levels of motorization in developed and developing nations are a global concern. The prospects for large increases in car ownership levels in countries like China and India, coupled with their size, will undermine any progress made in reducing emissions. In 2003, China had only 12 vehicles per 1000 people (compared to 100 in Brazil and 940 in the USA), but the average growth rate of motorization has been $12 \%$ per annum since 1990. In 2003, 4.4 million vehicles were built in China ( $4^{\text {th }}$ largest manufacturer in the world) and this is expected to increase to 20 million $\left(2^{\text {nd }}\right)$ in 2020 (68-69). Motorization has been strongest in the USA and the EU. In 20092.9 trillion vehicle kilometers (vkm) were recorded by all vehicles circulating in the USA (passenger cars, buses, and trucks, motorcycles) (70) making the USA responsible for $22 \%$ of the world total vkm driven (cf. 20:61). In the same year, the USA was also responsible for the largest vehicle stock in the world with 239 million vehicles, closely followed by the EU region with 239 million units (70). The responsibility for $\mathrm{CO}_{2}$ mitigation lies primarily with the developed world. 
The growth in the demand for domestic road transport has been slowing down in some industrialized countries (71-72), but it is too early to tell whether this decline in growth is a durable phenomenon, reflecting structural demand saturation. This stabilization does not extend to international air and maritime transport, or to developments in Asia and Latin America. Indeed, almost all forecasts and transport foresight studies (under the business as usual scenario) are in agreement that transport is expected to continue to increase at least until 2050 and probably beyond (e.g. 73). There are no real signs to suggest the limits to travel have been reached, and so the transport sector must be decarbonized to reduce the environmental problems related to travel.

\section{Decarbonizing transport}

Generally, decarbonizing means lowering the ratio of $\mathrm{CO}_{2}$ per unit of GDP (74), but in this review decarbonizing transport is defined as actions that lower that ratio using final transport energy use in the denominator. The scale of reduction of $\mathrm{CO}_{2}$ emissions needed is substantial, with long lead times for low $\mathrm{CO}_{2}$ technologies and a radical shift in lifestyle. Policy scenarios will have to target transport in terms of vehicle kilometers (vkm) traveled by cars and trucks, in addition to the technologies that reduce fuel consumption. Decarbonization has been put on the agenda in the Kyoto Protocol agreement (led by the United Nations Framework Convention on Climate Change), and more recently in the Copenhagen and Cancun summits. Yet, these agreements have not resulted in $\mathrm{CO}_{2}$ mitigation action in transport.

Motorization is responsible for $74 \%$ of world transport $\mathrm{CO}_{2}$ emissions (75), and per capita $\mathrm{CO}_{2}$ emissions grow in tandem with the development process (Figure 2). Technological leapfrogging paths, that avoid $\mathrm{CO}_{2}$ intensive transport systems (the IC engine powered vehicle or truck or bus), should enable nations to transition to low $\mathrm{CO}_{2}$ transport (76). Figure 2 shows that the Asia Pacific region is more $\mathrm{CO}_{2}$ efficient than the North American region. The question remains whether Latin America, China and other regions will move towards the North American group or towards the Asia Pacific group led by Japan. Leapfrogging to a low- $\mathrm{CO}_{2}$ transport system would provide significant co-benefits (lower obesity, improved health), as well as less dependency on imported oil.

\section{[Figure 2]}

$\mathrm{CO}_{2}$ emissions and fuel use in road transport are a function of the availability and condition of the transport infrastructure (affected by among others the availability and conditions of roads and the structure of the road network), the number of vehicles on the road (affected by among others affordability, consumer preference and fuel price), distances driven (affected by among others fuel price and tax policies e.g. car taxation, tolls or congestion charge) and the level of fuel economy of the cars (amount of motor fuel consumed per km driven per year). The personal vehicle has impeded the decarbonization of world transport activity because of the increase in vehicles size (which requires more energy input) and because of carbon lock-in, or the situation of durable and difficult-to-overcome dependence on non-renewable fossil fuels that is characteristic of the whole transport system. In other transport modes decarbonization is also impeded by the dominance of the jet turbine for aircraft, the diesel engine for ships and railways. 
Freight transport faces four challenges that must be tackled for decarbonizing the transport sector of OECD economies:

- The need to reduce off-shoring of manufacturing and $\mathrm{CO}_{2}$ leakage to regions outside EU and USA, so that $\mathrm{CO}_{2}$ emissions in global transport can be reduced;

- The need to allocate emissions reductions equitably, as a large quantity of $\mathrm{CO}_{2}$ emissions from the BRIC countries result from the export of goods to the OECD countries;

- The need to reduce consumption of key $\mathrm{CO}_{2}$ intensive products which stimulate transport and manufacturing $\mathrm{CO}_{2}$ footprints of China or other fast growing regions; and

- The need to introduce policies to support innovation in low $\mathrm{CO}_{2}$ transport in less developed nations.

Addressing these issues will help formulate the policy actions needed to decarbonize the transport sector and global supply chains.

\subsection{Policy mix for decarbonization}

The decarbonization of the world transport system requires a decoupling of economic growth from transport and emissions growth, through creative combinations (including socio-economic innovations) of new transport technologies and a reorganization of the ways in which travel and freight movements are undertaken. Table 1 summarizes the type of policy measures, their timing (or transition period) and the impacts that can be expected (although some are highly uncertain). Most of the solutions in Table 1 target road vehicles, as the major source of transport $\mathrm{CO}_{2}$ emissions.

\section{[Table 1]}

Of the measures described, the behavioral or demand side measures are the least popular and these are often neglected, as they are complex and multidimensional. Some measures in Table 1 have already been introduced and others have not. As for technology options in general and biofuels in particular, many of the options in Table 1 depend on the macroeconomic environment to determine whether these measures become profitable. High energy (fuel and oil) prices (or taxes) can enhance the monetary savings conferred by the technology chosen (i.e. hybrid cars, alternative fuels). While technology and demand side measures are commonly juxtaposed as alternative routes towards a decarbonized transport system (e.g. 77-78), we contend that they are better considered in conjunction with each other as they are interdependent. The use of many new technologies (e.g. electric vehicles) necessitates different practices and routines on the part of their users (see also 79).

WEC (80) suggests more than five power train options, using alternative fuels and electricity, for vehicles and it argues for an integrated planning approach that involves all major stakeholders. Bonilla (81) recommends a policy mix for long-distance freight transport and for vehicle fuel economy. From the development of technology niches to vehicle down weighting and business innovation taxes, policy approaches need to be holistic (Table 1). Policy approaches will have to rely on multiple strategies to decarbonize transport, as a single approach is not likely to produce the $\mathrm{CO}_{2}$ savings desired. For example, the EU Voluntary Agreement on passenger cars should be 
extended to all transport (aircraft, ships, trains and commercial vehicles), as there are no obligatory fuel economy standards for these modes.

The three key factors in transport policies for decarbonization are the policy framework, its underlying philosophy and its impacts. The current public policy framework for decarbonization is highly reliant on rational decision theory (82) and on expected utility theory (83), and these inform the dominant discourse on environmental economics (84). In the Friedman framework, consumers maximize expected utility from the policies that have emerged from government. In the Nordhaus framework (85), it is assumed policy makers will weigh costs and damages to arrive to a rational decision on decarbonization. In the Stern (62) framework, it is believed that early action in $\mathrm{CO}_{2}$ mitigation is the most cost-effective option, but this framework relies less on the conventional wisdom as it uses a much lower discount rate for future, in which damages to future generations are discounted less (i.e., valued more) than is done in the analyses of Nordhaus, Friedman and others. Other policies (Table 1) include fuel pricing and information which are at the heart of the rational decision maker (neoclassical economics), but other perspectives offer alternative policy options by acknowledging irrational behavior of consumers and of policy actors as explained below. The assumption of rational economic agents (consumers and producers) leads to the concept of cost-effectiveness. Cost-effectiveness is feasible under high learning rates and technological change as Koehler et al. (85) suggest.

The policy measures outlined in Table 1 for decarbonization take no account of the abatement cost argument. The IPCC (86) valued $\mathrm{CO}_{2}$ abatement costs in transport for new LDVs (Light Duty Vehicles - cars) in the OECD Europe region as costing $\$ 131$ per tonne of $\mathrm{CO}_{2}$ saved with oil prices at $\$ 30 /$ barrel in the high efficiency case (and \$58 per tonne of $\mathrm{CO}_{2}$ saved with oil prices at $\$ 60 /$ barrel). As there are no estimates of $\mathrm{CO}_{2}$ abatement costs for the entire freight and passenger sectors of the $\mathrm{EU}$ (or the world), it is difficult to know whether $\mathrm{CO}_{2}$ abatement costs are currently high or low, and future estimates remain highly uncertain.

Apart from costs, other mechanisms are needed to induce changes in individual, collective and corporate behavior. Nudges and cognitive processes can help to shift behavior for cost-effective policy options. Currently, estimates on cost-effective behavioral change policies are not well understood and rarely calculated, but recent research in energy use shows that it is cost-effective to implement behavioral change (87). The energy use and associated $\mathrm{CO}_{2}$ emissions are strongly dependent on technology (its supply or access to it) and the choices of the driver or traveler. Certain policies (Table 1) stand out, such as those that change the current business model, those that change behavior (nudge) and help avoid anchoring (88), and measures that target modal shift towards low- $\mathrm{CO}_{2}$ transport options, such as rail and cycling.

A key (non-price based) policy measure for decarbonizing transport is to trigger behavioral change of car buyers or drivers using 'nudges', and this policy should not exclude collective responses for decarbonizing transport (88). Following Thaler and Sunstein (88), a nudge is defined as any aspect of a choice set that alters behavior without foreclosing alternatives or significantly changing economic incentives. The intervention should be easy and cheap to reduce, for example a nudge could disclose information. Incentives for social entrepreneurship in the transport sector can also help. For example Yunus has proposed business innovation using micro-financing through local communities (the concept has been widely applied to other 
sectors), and a formula can be used to support mass transit projects (buses, trains, trams, bus rapid transit lines) (89).

Other more well-known policies such as fuel economy (or GHG) standards can also provide lower $\mathrm{CO}_{2}$ emissions. For instance, a target of $90 \mathrm{~g}-\mathrm{CO}_{2} / \mathrm{km}$ (new cars) could be adopted as a global target (90). This would require global car manufacturers and car makers of the BRIC economies to adopt the most stringent fuel economy standards. One possible disadvantage is that $\mathrm{CO}_{2}$ standards of new cars can lead to rebound effects (this is an increase in energy use as its price falls due to improved fuel economy) on fuel consumption (91-92). Standards (limits on emissions) on unit emissions (GHG/vkm traveled) are absent in all modes except for the private car, and even here the levels are set nationally or by groups of nations (e.g. EU) not globally. Fast growing sectors, such as vans, need to be included in emissions agreements, so that the EU Voluntary Agreement or CAFE (USA) is widened, and it is only through mandatory agreements that effective action is possible.

Further policies would include adopting an active travel strategy aimed at increasing walking and cycling (93). Active travel is attractive because it brings co-benefits beside the fuel-saving effects of walking and cycling (not tabulated in Table 1). Policy innovation involves seeing $\mathrm{CO}_{2}$ emissions cuts as a co-benefit, so that actions to mitigate emissions (and climate change) also tackle other objectives, such as disease prevention and the promotion of public health (94). The decarbonization of transport has emerged in the environmental-transport discourse, but it has focused almost exclusively on techno-optimism and less on behavioral solutions. In our opinion, the decarbonization of transport needs to be linked to wider policy goals, such as health, trade, macroeconomic stability, energy efficiency and security. It can be seen as part of the green economy if co-benefits are included as part of the inventory of measures.

\section{Rethinking transport governance}

While the need for decarbonizing transport is evident and GHG reductions can be pursued through many different interventions, it has so far been difficult to achieve sizable emission reductions from transport. One set of reasons for this paradox, beyond the important economic and societal benefits from transport, lies in the ways in which transport's decarbonization has often been conceptualized and pursued. These ways are path dependent, and they are to a considerable degree patterned by modes of thinking about (and intervening in) transport systems that came into existence in an era when transport governance was primarily aimed at facilitating the growth of carbon-intensive transport activity. In our opinion and that of others (e.g. 95-96), transport governance needs to be rethought in a number of ways if large-scale decarbonization of the transport sector is to be achieved.

\subsection{The historical legacy of transport governance}

Historically, most interventions in transport systems were aimed at facilitating the growth of transport activity. Given that road based transport became locked into dependence on the internal combustion engine in the late 1800s due to a string of contingencies, transport governance 
became trapped in carbon lock-in (97). These processes have been documented by multiple authors drawing on evolutionary and/or complexity theory (33, 98-103).

Transport governance needs to be understood in the context of the automobile-based transport system as a socio-technical system (e.g. 98-101). Such systems reproduce themselves through positive feedback loops and increasing returns. Transport governance is seen as the outcome of interactions between multiple stakeholders - public authorities, transport industry, research institutions, the public, and so on - and is a crucial aspect of the socio-technical regime, namely the practices, cognitive routines, competences and materialities that pattern and continually reproduce the system.

The embeddedness of transport governance within the socio-technical system of automobility also means that contemporary ways of thinking about and intervening in (road) transport bear traces from previous eras. They still owe a great deal to the creation of national highway systems (104), the development of expert knowledge about the functioning and optimization of flows within transport networks (105), and the predict and provide approach to governing automobile transport in the decades following World War II. In this research informed approach to transport planning, "demands [were] projected, equated with need and met by infrastructure provision at least in as far as the public purse [would] allow" (55:44).

The growth and stability of the (global) socio-technical systems of aviation and maritime transport of passengers and freight have so far not been analyzed through the lenses of evolutionary and/or complexity theory. Such analyses are urgently required, as they may help us to further understand barriers to decarbonization in those carbon-intensive forms of transport, and because butterfly effects (106) may occur, whereby small changes in one actor within those systems may have large consequences for the system as a whole. Based on the information discussed in Sections 2 and 3, we contend that the evolutionary approaches advocated by Unruh, Geels and others could be applied effectively to transport.

\subsection{Modalities of path-dependent transport governance}

The historic emergence of transport governance from within carbon intensive socio-technical systems both enables and constrains current attempts to decarbonize the transport sector. Path dependencies occur in multiple interrelated domains (see also 107-108). The first pertains to the sunk costs of the existing material infrastructures for transporting people and goods. Those infrastructures are in place; abandoning them and/or replacing them with more sustainable alternatives, if at all possible, would be extremely costly and cost-ineffective. The others, discussed below, relate to the type of instruments proposed to decarbonize transport, how transport is understood, and the implementation of instruments.

Instruments. While transport governance and especially public policies in the Western world have moved beyond predict and provide to embrace sustainability to more or lesser degree (55, 109), not all of the available instruments to reduce transport's environmental impacts are equally likely to be pursued. Analyzing how actors within a socio-technical system seek to overcome the dependence on fossil fuels, Unruh (110) distinguishes three ideal typical approaches: 
- End-of-pipe (EoF) measures that leave the system intact but treat externalities such as emissions. Examples include catalytic converters and the CAFE standards in the USA

- Continuity measures: incremental or intra-system innovations that maintain the overall system architecture and maximize similarities between the existing and reconfigured system. Examples include the replacement of the internal combustion engine by electric, hybrid and fuel cell vehicles.

- Discontinuity measures: radical, inter system innovations or transitions resulting in the complete abandonment or replacement of an existing system, as with the promotion of transit oriented design (TOD) at the urban level and the development of high speed trains (HST) at the (inter)national level.

Unruh's scheme is crude and the distinction between continuity and discontinuity is vague and context-dependent: what counts as a radical innovation in some geographical contexts counts as a continuity approach elsewhere. A case in point is transit oriented developed, which has a long history in some countries and urban areas, such as the Netherlands, Portland in the USA and Curitiba in Brazil (111-112), but would be a radical innovation in the context of, say, Phoenix (AZ), Fresno (CA) or Beijing. Nonetheless, Unruh's scheme usefully brings out the preference for conservative approaches among policy makers and other stakeholders within a sociotechnical system. They tend to resort to EoF measures first and, if these are insufficient, to continuity approaches; discontinuity approaches are much rarer and often require that the state of lock-in is overcome first. The (past) preference for EoF measures in the context of transport's environmental impacts has already been documented in Section 2.1 above.

Discontinuity approaches are radical innovations for some actors but can be understood and reappropriated by others as having a symbiotic, continuous relationship with existing systems. HST in a number of European countries exemplifies this situation. Some actors (e.g. environmental lobby organizations) promoted HST as an alternative to intra continental air travel, and the air transport sector in Germany, France and the Netherlands has been successful in tacking such airports as Frankfurt, Charles de Gaulle and Schiphol onto the European HST network. The HST-aviation relationship has successfully been translated from discontinuous into continuous (113). This example suggests how difficult it is to enact radical change from within the existing socio-technical regime.

Understandings. Past attempts to govern transport co-evolved and co-emerged with particular inter-subjectively shared discourses, or ensembles of ideas, concepts and categories through which transport and other phenomena are understood and interpreted by policy makers, professionals and researchers (114). The fundamentals underpinning transport related discourses are heavily influenced by scientific and 'expert' understandings of transport, and they also tend to change rather slowly. Therefore, historically emerged discourses continue to structure thinking about how transport can be decarbonized by researchers, policy makers and lobby organizations in important ways (107).

While those transport related discourses are by no means monolithic and homogeneous, it is fair to say that they are heavily infused with concepts, metaphors and methods from engineering and neo-classical economics (and more recently from the psychological sciences). While insights from these disciplines have greatly aided our understanding of transport systems, they also 
constrain thinking about how to enact systemic changes towards low carbon transport. Such constraints arise in particular from a few basic assumptions - typically black-boxed (115) and left unmentioned yet intimately bound up with free market economics, Taylorism, Fordism and the very system architecture that produced carbon lock-in - about the ontology of transport systems (Table 2). These principles have all been challenged by some academic researchers (e.g. $56,95,107,116)$ but are built into most operational models and techniques to quantify the effects of interventions in transport systems on travel demand by governments and other stakeholders used in applied research. The use of those models and techniques, which is widespread in the transport community $(79,116)$, predisposes attempts to decarbonize transport towards a belief in technological solutions, the provision of physical infrastructures and land use configurations conducive to low carbon transport and $\mathrm{CO}_{2}$ pricing/budgeting in transport, whilst (subtly) shifting attention away from other potential instruments, such as attempts to reconfigure societal values and expectations or the representation of particular forms of carbon-intensive transport in the media. Hence, although the transport research community is far from monolithic, the view that technological improvements (cleaner fuels, fuel economy), pricing and TOD are the most effective ways to decarbonize automobile based surface transport is widespread among transport researchers and policy-makers (e.g. 117-118).

\section{[Table 2]}

Implementation. Path dependence also occurs with regard to rules - the formal and informal procedures, routines, norms and conventions that coordinate and structure the actions of public authorities, transport industry, lobby groups and so on $(99,107,119)$. These rules prohibit radical change in transport governance, signaling institutional lock-in, in at least two ways. First, despite experiments with bottom-up and participatory approaches based on communicative planning models in specific cities and settings (120-122), the governance of transport systems remains in many instances a technocratic exercise that is strongly driven by technical expertise, exclusionary in that only a sub-set of stakeholders is involved, and organized in a top-down manner. As a result, the structural bias towards determinism, instrumental rationality and technology push continues to be reproduced continually in transport governance (104, 122-123).

Second, the predisposition towards Fordist specialization and compartmentalization is so wired into transport governance's rules that the (rhetoric) ideals of coordination and holism are difficult to carry through into real-world planning practice. The idea that the compartmentalization of responsibilities represents a significant challenge to transport governance is far from new (124126) but becomes all the more pressing in those instances where a wider range of stakeholders is involved in transport governance. The degree of compartmentalization is indicated by planning at the transport land use nexus. Within most countries, land use planning tends to be a responsibility of local public authorities. However, finance for major (transport) projects comes from national government and increasingly from private investors, whilst implementation is often in the portfolio of other sub-national authorities entities. Vertical power relations are thus very complex. These are compounded by horizontal power relations, given that responsibilities for land use and transport are often split across multiple agencies at the same level of government with often no department taking overall control. Further, department and agencies concerned with the environment have become increasingly involved in transport and land use planning. These often work according to different rules and put more emphasis on collaborative 
and open approaches to planning, which contrasts with the more much more institutionalized and rigid systems of control traditionally associated with transport planning: integrated policies across sectors create additional complexity in rules (127). Finally, when considering the global context and increasing internationalization of our transport infrastructures, better coordination in and amongst countries is required, yet the complex tapestry of varying routines and institutional arrangements actually makes fragmentation worse and integration more difficult (128).

It is not surprising that such fragmented institutional arrangements frequently produce public policy agendas lacking a clear direction, ineffectual, piecemeal and convoluted policies, over reliance on technical expertise, powerful pro-growth lobbies, and continued carbon lock-in. In Melbourne, for instance, the fragmentation of public transport agencies alongside a more effective and powerful road planning agency and lobby and the inheritance of rules from the past implied that investment in road transport continued unabated after the predict-and-provide approach had been abandoned and sustainability discourses had become more prevalent among stakeholders (107).

\subsection{Opening up the paths of transport governance}

Whilst the historical legacy of transport governance matters in attempts to decarbonize transport, complexity theorists (129-130) emphasize that path dependencies are not clad in stone, suggesting that socio-technical trajectories can be opened up in a variety of ways, some of which are amenable to public policy (131). Insights from the multi level perspective (MLP) on sociotechnical transitions $(100,119,132)$ are clearly relevant here. Proponents of this MLP identify the micro-level of socio-technical niches and macro level of the socio-technical landscape alongside the aforementioned socio-technical regime at the meso-level. Niches are initially unstable socio-technical configurations where radical innovations emerge, acting as incubation rooms where innovations are protected from market mechanisms, as they are carried and developed by small networks of dedicated actors, who may or may not be influential within the existing regime (100). The landscape is the exogenous environment that cannot be readily influenced by niche and regime actors. It includes, for instance, macro-economics, macropolitical developments, cultural trends, and tends to change rather slowly. The MLP's key idea is that radical change, whereby niche-developments durably transform the regime, comes about through interactions at the three levels, with niches building up internal momentum, landscape developments exerting pressure on the regime, and destabilization of the regime creating windows of opportunity for niche-innovations (132). The exact nature of transition pathways depend on the timing of landscape pressure vis-à-vis the development stage of niche innovations, the degree to which landscape changes disrupt rather than reinforce the regime, and whether niche innovations have a competitive or symbiotic relationship with the regime (119).

A well-developed literature now exists about how public policy can assist in niche development in non-disruptive ways. According to the transition management perspective $(96,131,133)$, public authorities can instigate an iterative and adaptive multi-actor process of creating transition arenas (new institutions where niche actors can interact, exchange knowledge and learn), formulating interim objectives and long-term visioning, conducting real-world experiments, evaluation, creating public support and broadening of the coalition. In this process public 
authorities do not create niches in a top-down manner but function as process manager and initiate strategic experiments (131-133).

Transition management has been implemented in energy and transport policies in the Netherlands, with varying levels of success (96,133-134). One challenge is the tendency in niche experiments to push for a certain technology and to neglect the necessary co-evolutionary social and cultural dynamics (100, 134-135). Other concerns that have been identified in the literature include the limited involvement of the general public and disregard for how people bring about (or obstruct) transitions in their everyday lives $(133,135)$, the focus on short-term goals $(96)$, and the risk of early lock-in because major investments in material infrastructures are required (134). Hence, we suggest, public authorities at local, national and supranational levels seeking to decarbonize transport should try to stimulate the emergence of niches that not only evolve around new technologies. They should of course facilitate the maturing of technological novelties. Once a window of opportunity opens ups, regime change may occur more quickly when a dominant design for a carbon extensive transport technology has been established than when several alternative designs are still competing for dominance (cf. 119). However, they should also stimulate the development of new scientifically informed discourses for understanding transport that emphasize non-determinism, unpredictability and more-thaninstrumental rationalities, and help these diffuse into the realms of transport planning and practice. Examples of such discourses include the emerging literature on transport as an evolutionary and complex system $(97,108,119)$ and the 'new mobilities paradigm' in cultural sociology, geography and cognate fields $(31,105)$. Their development is likely to provide innovative ideas about how transport can be decarbonized, and these ideas could be implemented in further niche experiments. The emergence of niches centered on new rules can be stimulated, and new organizations can be created where responsibilities for regulation, development and maintenance of material infrastructures, information provision and contacts with system users and so on, are all concentrated.

Finally, given that the power of niches to replace or reconfigure regimes depends on landscape pressures, public authorities at local, national and supranational scales can try to induce landscape changes. Educating the general public about the relationships between transport, energy use and climate change can be one strategy to contribute to cultural change (110). Restrictions on advertisements promoting $\mathrm{CO}_{2}$ intensive modes of transport in the media or during public events (not unlike the bans on ads for smoking and alcohol in some countries) and fiscal measures favoring low carbon transport provide other examples. This may help to reconfigure the cultural dimensions (i.e. the symbolic meanings) of people's everyday travel behavior, which are crucial to the eventual emergence of a low-carbon transport system but often overlooked in the transition management literature (135). In short, a focus on niches only will not suffice on its own, as the means by which the landscape should in our view be affected varies from place to place and according to the type and scale of transport. Global panaceas are unlikely to be identifiable.

\section{Conclusions}


Actions to decarbonize transport must be taken sooner rather than later in both developed and developing nations, as transport has made no contribution to reducing $\mathrm{CO}_{2}$ emissions. Yet, transport's decarbonization constitutes a key challenge for various reasons. First, it is not always clear where - in which countries - transport related emissions should be reduced. The debate is already highly complex and contested (136), and the global distribution of GHG reduction responsibilities is complicated further by the rapid growth of international aviation and maritime transport (which outpaces that of vehicle). If the current production-based emissions accounting system is used, it is difficult to assign emissions to the economic agents and countries that are primarily responsible for their generation and international movements will be allocated to the exporting instead of the importing country. Given the emergence of the BRIC economies (which are mainly exporters), future reduction responsibilities will shift to non-OECD countries (over and beyond the shift resulting from the increase in domestic transport in those countries). Naturally, this approach to responsibilities for GHG reductions in international transport is unpopular among non-OECD countries, as it ignores the fact that much (intercontinental) transport is a direct consequence of the off-shoring of manufacturing from OECD to developing countries. A consumption-based approach to national emissions accounting, which considers global supply chains and allocates emissions to end users (137), would revert responsibilities for GHG reduction in (international) freight transport back to OECD countries. The implementation of a consumption based approach by UN institutions is unlikely in the short run, because of resistance by OECD countries. The lack of agreement about the international division of responsibilities may delay the undertaking of concrete action to reduce emissions from international freight transport. Yet, even if global agreement on $\mathrm{CO}_{2}$ mitigation were reached, a radical rethinking of how global supply chains are organized would be required. Otherwise international (freight) transport will consume an ever increasing share of the global $\mathrm{CO}_{2}$ budget.

Given transport's major economic and societal benefits, policy-makers, and many lobby organizations and other stakeholders, often hesitate to actually act to reduce or limit transport demand (even when official government documents suggest that this is required). Frequently, policy makers seem to prefer to maintain, and even increase, transport volumes (vkm and freight) to facilitate economic growth albeit at lower environmental cost by promoting modal shift and technology oriented interventions, such as cleaner fuels and tighter fuel economy standards. Thus, in the transport sector, the UNEP's notion of green economy (138) is taken to mean larger investment in transport infrastructure (to facilitate economic growth) for sustainable transport modes, especially public transport. The Brazilian city of Curitiba is often invoked as a success story in this regard (138-139). In the Global North and the USA in particular, investment in highspeed train (HST) is currently seen and used as one means of revitalizing the economy after the credit crunch but in a sustainable manner (140). However, there is neither convincing evidence nor any general agreement that such investments affect and/or facilitate economic growth. Even if there were, based on lessons from the past (Section 2), caution should be exercised about the net impact in terms of $\mathrm{CO}_{2}$ emissions of large-scale investments in new transport infrastructures or technological systems. There is a real risk that overall emissions grow because of increased total transport volumes (as substitution of $\mathrm{CO}_{2}$ intensive transport modes is often limited). Obviously, this growth in emissions will be smaller than if $\mathrm{CO}_{2}$ intensive (IC engine based) forms of transport are promoted. Yet, the possibility of increased emissions suggests that the business as usual approach of mitigating transport's GHG emissions through infrastructural and technology oriented interventions is not enough to decarbonize transport. This may even hold 
when infrastructure investment is integrated with land use planning, as evidence from the Netherlands suggests. While a long tradition of integrated transport and land use planning exists in that country (111), the per capita vkm continues to grow at a faster rate than that for sustainable modes (141). Integrated planning has only dampened the growth rate of vkm (111, 142).

Path dependencies in the understandings of, and interventions in, transport systems further complicate decarbonization efforts. Research and theories about socio-technical transitions may allow the pathways of transport governance to be recast. However, transitions management can become fraught with difficulty in practice (cf. 100), and the socio-technical transitions literature has concentrated on road transport within a western and national context $(96,101,134)$. It has remained well nigh silent about international aviation and maritime transport and non-western contexts. The ways in which public policy can stimulate niche development probably need to be rethought if the transition management perspective $(96,133-134)$ is to be applied to those forms of transport and contexts. This is because public institutions will often be less powerful and/or because multiple national and international public authorities with different responsibilities, powers and routines will be involved. The dynamics of transition arenas will thus be considerably different from what can be expected in Western European countries. More conceptual thinking about and practical experimentation with transition management is required.

In sum, while the prospects for transport's decarbonization are not optimistic and past attempts have yielded only limited success, action is urgently required. We believe that a radical holism is required that moves beyond the progressive interventions already undertaken in such countries as the Netherlands. This radically holistic approach would not focus primarily on passenger surface transport but also set out to enact step changes in the freight sector and the international transport of people and goods. It would move beyond business as usual approaches to GHG emissions reductions based on technological optimism and investment in 'green' infrastructures. Rather it would mobilize the full range of possible interventions (including travel demand reduction) in existing transport systems, including the pricing of $\mathrm{CO}_{2}$ consumption, information campaigns and unconventional instruments not normally considered in transport policy (e.g. bans on commercial advertisements for high $\mathrm{CO}_{2}$ vehicles or types of travel). Further, this approach would include new ways of understanding transport systems based on complexity theory and transition theory, and address issues of implementation in transport governance so that intentions and plans become realized in actual practice. Fundamentally, it would question the merits of and potential for reducing transport congestion, and it would be very cautioned, even prohibitive, with respect to investments in motorized transport infrastructures. Finally, it would involve alternative, more equitable ways of weighing the economic and societal effects and environmental impacts. As a result, the Earth's long-term future would no longer be discounted in favor of short-term, local gains specific to one or a few countries; emissions reduction in transport would be married to the achievement of the Millennium Development Goals (138); the functioning of the global economy would be reconsidered; and existing inequalities in decarbonization responsibilities and between the global North and South would be redressed. 